\title{
Hypocenter Relocation of Volcanic Earthquake at Agung Vulcano
}

\author{
Reni Agustiani ${ }^{1}$, Bagus J. Santosa ${ }^{1}$, Yasa Suparman², Devi K. Syahbana ${ }^{2}$,Gazali Rachman ${ }^{3}$
}

\begin{abstract}
Agung Volcano is a stratovolcano located in the area of Karangasem regency of Bali and is in the northwestsoutheast fault alignment with Batur, Abang and Seroja Volcano. The existence of this alignment allegedly related to the fracture in the northwest of the island of Bali. The eruption of Agung Volcano recorded on November 25th, 2017 was a significant danger for people living around it. Therefore, it is necessary to monitor the activity of Agung Volcano. The method used in this study is the relocation of volcanic earthquake sources to determine the location of the source of the earthquake which caused an increase in Mount activity. Hypocenter relocation was carried out on 138 earthquake events during October 2017-January 2018 using the Coupled VelocityHypocenter method. Hypocenter was obtained at a depth of less than $10 \mathrm{~km}$ under sea level with an RMS value $<0.3$ seconds, and this is thought to have a flow of magma fluid through the conduit which moves towards the earth's surface and triggers an eruption.
\end{abstract}

Keywords-Agung Vulcano, Coupled Velocity-Hypocenter, Volcanic Earthquake Relocation.

\section{INTRODUCTION}

Volcanic-tectonic earthquakes are earthquake events that occur due to changes in pressure on solid rock due to injection or pulling of magma that moves to fill empty spaces. This earthquake can occur before and during volcanic eruptions. The injection of magma into the surrounding rock creates pressure on the rock which eventually results in an earthquake as a result of the addition of crack to the rock. The activeness of volcanictectonic earthquakes shows an increase in seismic activity in the body of the volcano and as an indication that volcanoes will erupt[1]. Increased volcanic earthquake activity at Mount Agung began in September 2017. Finally, eruption or eruption occurred on November 25, 2017[2]. The volcanic eruption is an extract that releases volcanic materials in the form of gas, dust, lava flows, rock fragments, and others[3]. Mount Agung is a stratovolcano located on Bali Island, Indonesia. The geographic peak position is on latitude 08 o 20 ' 30 "and longitude 115o 30' 30", it has an altitude of 3142 mean sea level[4]. Mount

\footnotetext{
${ }^{1}$ Reni Agustiani and Bagus J. Santosa are with Department of Physics, Institut Teknologi Sepuluh Nopember, Surabaya, 60111, Indonesia. Email: reniagustiani93@gmail.com; bjs@physics.its.ac.id.

${ }^{2}$ Yasa Suparman and Devi K. Syahbana are with Center of Volcanology and Geological Hazard Mitigation, Jl. Diponegoro No.57, Bandung 40122, Indonesia.

${ }^{3}$ Gazali Rachman is with Physics Education Department, Faculty of Teacher Training and Education, Universitas Patimura, Jl Ir. M. Putuhena, Kampus Poka, Ambon, Maluku 97233, Indonesia
}

Agung considered as one of the most dangerous volcanoes of Indonesia because of the densely populated surrounding. Based on this, it is necessary to analyze Mount Agung's seismic data. Thus, in this study, an earthquake hypocenter relocation was conducted to determine the location of the source of the earthquake that caused the eruption. Besides, also obtained of both the 1D earth velocity model and station correction.

\section{COUPled Hypocenter Velocity Model}

The arrival time of a seismic wave generated by an earthquake is a nonlinear function of the station coordinates (s), the hypocentral parameter (origin time (t) and geographic coordinates $(\mathrm{x}, \mathrm{y}, \mathrm{z}, \mathrm{t})$ ), and velocity field (m). In general, neither the true hypocentral parameter nor the velocity field is known. With arrival times and station location being the only measurable quantities, we cannot find the observation times ( $\left.\mathrm{t}_{\mathrm{obs}}\right)$. To proceed, we have to make an educated guess about the unknown parameters. Using an apriori velocity model, we trace rays from a trial source location to the receivers and calculate theoretical arrival times $\left(t_{c a l}\right)$. The differences $(\Delta)$ between the observed and the calculated arrival time, the residual travel time ( $t_{\text {res }}$ ), can be expanded as functions of the differences between the estimated and the true hypocentral and velocity parameters[5].

$$
\begin{aligned}
t_{i}^{r e s} & =t_{i}^{o b s} \\
t_{i}^{r e s} & =\sum_{k=1}^{4} \frac{\partial f}{\partial m_{k}} m_{k}
\end{aligned}
$$

$m_{k}$ is the differences of 4 hypocenter parameters $(\mathrm{t}, \mathrm{x}, \mathrm{y}, \mathrm{z})$ estimated and true. If it formed in the matrix, Eq. 2 becomes:

$$
\begin{gathered}
\left(\begin{array}{c}
\Delta t_{1} \\
\Delta t_{2} \\
\vdots \\
\Delta t_{n}
\end{array}\right)=\left(\begin{array}{cccc}
\frac{\partial t_{1}}{\partial T} & \frac{\partial t_{1}}{\partial x} & \frac{\partial t_{1}}{\partial y} & \frac{\partial t_{1}}{\partial z} \\
\frac{\partial t_{2}}{\partial T} & \frac{\partial t_{2}}{\partial x} & \frac{\partial t_{2}}{\partial y} & \frac{\partial t_{2}}{\partial z} \\
\vdots & \vdots & \vdots & \vdots \\
\frac{\partial t_{i}}{\partial T} & \frac{\partial t_{i}}{\partial x} & \frac{\partial t_{i}}{\partial y} & \frac{\partial t_{i}}{\partial z}
\end{array}\right)\left(\begin{array}{c}
\Delta \mathrm{t} \\
\Delta \mathrm{x} \\
\Delta \mathrm{y} \\
\Delta \mathrm{z}
\end{array}\right) \\
d_{i}=\sum_{j=1}^{M} G_{i j} m_{j} \quad ; i=1,2, \ldots, N
\end{gathered}
$$

Equation 4 is the result of forward modeling. Because the arrival time of the ray observation is equal to the amount of initial time and travel time, then all elements $\frac{\partial t_{i}}{\partial T}$ in the first column of Eq 3 are 1. Equation 4 will not be stable if the number of models (M) parameters is smaller than the amount of data $(\mathrm{N})$. Therefore, the least square method is applied to minimize the error value (E) and obtain the $\mathbf{m}$ model solution in equation 5 . 


$$
\begin{aligned}
& E=\sum_{i=1}^{N}\left(\sum_{j=1}^{M} G_{i j} m_{j}-d_{i}\right)^{2} \\
& E=\sum_{i=1}^{N}\left(\sum_{j=1}^{M} G_{i j} m_{j}-d_{i}\right)\left(\sum_{k=1}^{M} G_{i k} m_{k}-d_{i}\right) \\
& E=\boldsymbol{e}^{T} \boldsymbol{e}=[\boldsymbol{d}-\boldsymbol{G} \boldsymbol{m}]^{T}[\boldsymbol{d}-\boldsymbol{G} \boldsymbol{m}] \\
& E=\boldsymbol{d}^{T} \boldsymbol{d}-\boldsymbol{d}^{T} \boldsymbol{G} \boldsymbol{m}-[\boldsymbol{G} \boldsymbol{m}]^{T} \boldsymbol{d}+[\boldsymbol{G} \boldsymbol{m}]^{T} \boldsymbol{G} \boldsymbol{m} \\
& \frac{\partial E}{\partial \boldsymbol{m}}=-\boldsymbol{d}^{T} \boldsymbol{G}-\boldsymbol{G}^{T} \boldsymbol{d}+\boldsymbol{G}^{T} \boldsymbol{G} \boldsymbol{m}+[\boldsymbol{G} \boldsymbol{m}]^{T} \boldsymbol{G} \\
& 0=2\left(-\boldsymbol{G}^{T} \boldsymbol{d}+\boldsymbol{G}^{T} \boldsymbol{G} \boldsymbol{m}\right) \\
& \boldsymbol{m}=\left[\boldsymbol{G}^{T} \boldsymbol{G}+\boldsymbol{\vartheta} \boldsymbol{I}\right]^{-1} \boldsymbol{G}^{T} \boldsymbol{d}
\end{aligned}
$$

The $\boldsymbol{G}^{T} \boldsymbol{G}$ matrix is a square-sized matrix $(\mathrm{M} \times \mathrm{M})$ according to the model parameters sought. $\boldsymbol{\vartheta}$ damping vector dan $\boldsymbol{I}$ identity matrix, both of which are used to stabilize the system[6].

\section{DATA AND METHOD}

The data used in this research is data from the seismic station of PVMBG, which is the Center of Volcanology and Geological Hazard Mitigation. Hypocenter relocation of the volcanic-tectonic earthquake used data recorded from October 2017 until January 2018 with the total number of eight stations. They are ABNG, BATU, CEGI, DUKU, PSAG, REND, TMKS, and YHKR [Figure 1].

Determination of the 1D velocity model and hypocenter relocation simultaneously in this study using the velest 3.3 software. Inversion method to get the model in the software using the Coupled Velocity-Hypocenter method. Initial input data includes earthquake parameters, initial velocity model [Table 1], travel time, and coordinates of earthquake recording stations obtained from PVMBG. Then it is compiled to get a new $1 \mathrm{D}$ velocity model (Vp, Vs) and a new hypocenter location. The earthquake data used were 138 earthquake events that occurred during October 2017January 2018. The type of earthquake used was deep volcano-tectonic (VT-A) because it was associated with rising magma to the surface with fractures in the rock causing the earthquake.

\section{RESUlt}

Based on the results of the new Velest velocity model [Figure 2] it can be seen that there are differences in $\mathrm{P}$ and $\mathrm{S}$ wave velocity models between the initial model and the final model. The P and S wave velocity models have not experienced changes in velocity at depths above $4 \mathrm{~km}$. It shows that the number of earthquakes in the depth range above $4 \mathrm{~km}$ is relatively small so it is unable to change the $1 \mathrm{D}$ velocity model produced. Changes in the new velocity model to the initial velocity model influenced by the position of the earthquake source corrected by each recording station so that a new $1 \mathrm{D}$ velocity model can be obtained that matches the current medium conditions.

Figure 3 Shows the earthquake before being relocated and after relocation with the Root Mean Square (RMS) value $<0.3$ seconds. If you see a horizontal (epicenter) and vertical (hypocenter) distribution, the earthquake before relocation (Figure 3a, c) shows a relatively more diffuse spread than the earthquake after relocation (Figure 3b, d).
The earthquake epicenter after being relocated tended to cluster in the northwest of the summit of Mount Agung. It is thought to be the source of the earthquake originating from the alignment of the fault structure with Mount Batur, Mount Abang, and Mount Saroja which trending northwestsoutheast. The fault which located northwest of the summit of Mount Agung is allegedly used by the magma fluid as a pathway to migrate to the gathering place of magma or directly to the surface. The fracture that the magma fluid passes through will become active again in carrying out rock movements due to stress. This fault is thought to be related to the lithospheric fracture in the northwestern part of Bali. Therefore, the Hypocenter of the earthquake tends to be at a depth of fewer than 10 kilometers and looks more focused and docked to form a stream towards the summit of Mount Agung. Large and small circles depend on the magnitude and size of the magnitude. The smallest magnitude is $0.8 \mathrm{SR}$, and the largest magnitude is $3.3 \mathrm{SR}$. Large magnitudes are associated earthquake events that have considerable discharge energy, while small magnitudes are associated small release energies. The released energy is caused by the elasticity of the rock that has reached the maximum limit due to stress is given by the movement of magma to the surface, so that the rock experiences cracks or even faults that can cause the release of energy called earthquakes.

\section{CONCLUSION}

This study uses primary and secondary wave propagation. Essential factors in determining earthquake hypocenter are wave arrival time (tp, ts), wave velocity (Vp, Vs), and origin time. The resulting $1-\mathrm{D} P$ and $S$ wave velocity models do not experience changes in velocity at depths above $4 \mathrm{~km}$. It is because the number of earthquakes at a depth of more than $4 \mathrm{~km}$, is relatively small so it is unable to change the $1 \mathrm{D}$ velocity model produced. While the hypocenter of the relocation results more closely form a magma path to the summit of Mount Agung.

TABEL 1.

INITIAL 1D VELOCITY

\begin{tabular}{ccc}
\multicolumn{3}{c}{ INITIAL 1D VELOCITY } \\
\hline Depth & Vp initial & Vs initial \\
\hline-3000 & 3.290 & 1.901 \\
0 & 3.841 & 2.220 \\
1000 & 4.920 & 2.843 \\
2000 & 5.211 & 3.012 \\
3000 & 5.578 & 3.224 \\
4000 & 5.952 & 3.440 \\
10000 & 6.158 & 3.559 \\
12000 & 6.439 & 3.721 \\
16000 & 6.890 & 3.982 \\
20000 & 7.410 & 4.283 \\
30000 & 8.000 & 4.624 \\
\hline
\end{tabular}


The $4^{\text {th }}$ International Seminar on Science and Technology
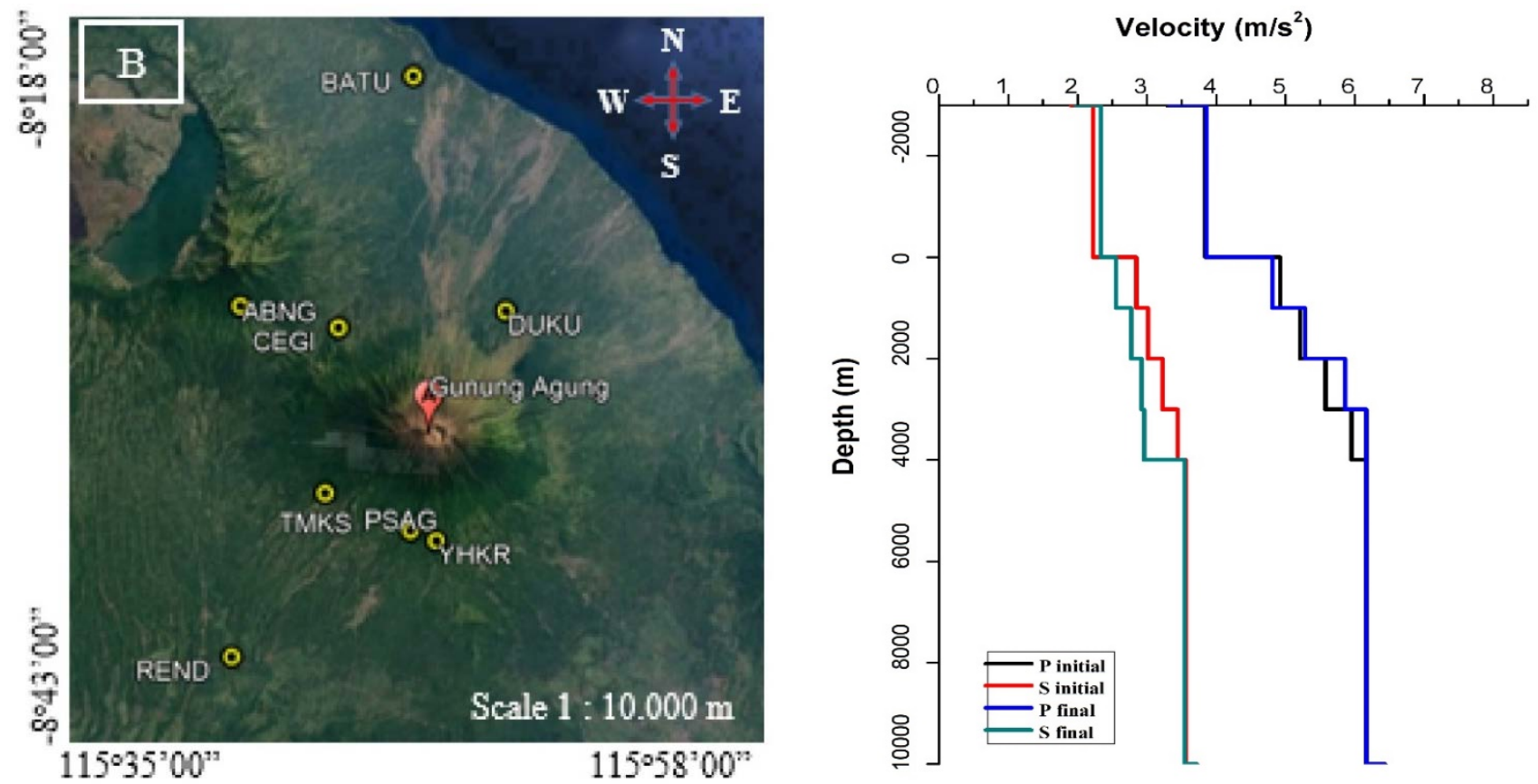

Figure 1. A map of the seismic stations found in the Agung volcano is used to the relocation of volcanic earthquakes
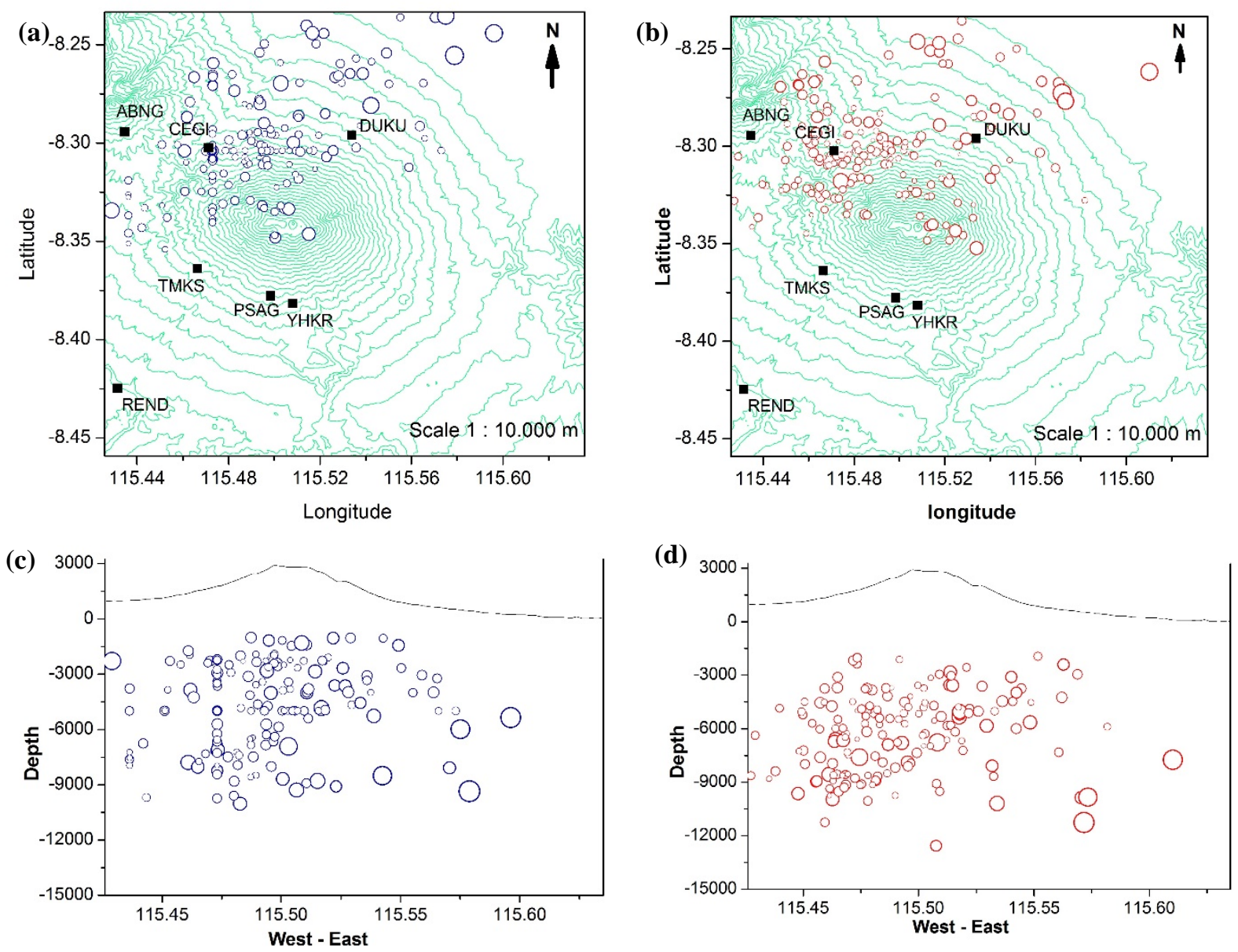

Figure 3. Source of the volcanic earthquake before relocation (left) and volcanic earthquake quake after relocation (right). Epicenter distribution (above) and transverse slices from the west-east (bottom). 
The $4^{\text {th }}$ International Seminar on Science and Technology August $9^{\text {th }}$ 2018, Postgraduate Program Institut Teknologi Sepuluh Nopember, Surabaya, Indonesia

\section{REFERENCES}

[1] B. A. Chouet, "Long-period volcano seismicity: its source and use in eruption forecasting," Nature, vol. 380, no. 6572, pp. 309-316, Mar. 1996.

[2] MAGMA Indonesia, "Information." [Online]. Available: https://magma.vsi.esdm.go.id/.

[3] F. Brenguier et al., "4-D noise-based seismology at volcanoes: Ongoing efforts and perspectives," J. Volcanol. Geotherm. Res., vol. 321, pp. 182-195, Jul. 2016
[4] K. Kusumadinata, Data dasar gunungapi Indonesia. Bandung: Departemen Pertambangan dan Energi, 1979.

[5] E. Kissling, W. L. Ellsworth, D. Eberhart-Phillips, and U. Kradolfer, "Initial reference models in local earthquake tomography," J. Geophys. Res. Solid Earth, vol. 99, no. B10, pp. 19635-19646, Oct. 1994.

[6] U. Kradolfer, "Seismic tomography in Switzerland using local earthquake," Eidgenössische Technische Hochschule (ETH) Zürich, 1989. 